\title{
MARCA PRÓPRIA: OPORTUNIDADE DE PARCERIA PARA PEQUENAS E GRANDES EMPRESAS
}

\section{PRIVATE LABEL: PARTNERSHIP OPPORTUNITY FOR SMALL AND LARGE COMPANIES}

\begin{abstract}
Caroline Dias Passos iD
Doutoranda em Projetos na Universidad Internacional Iberoamericana - UNINI.

E-mail: caroline.passos@gmail.com
\end{abstract}

Andressa Teles iD

Professora pesquisadora

Universidad Autónoma de Baja California Sur.

E-mail: and.teles84@gmail.com

Submetido: 21 jun. 2021.

Aprovado: 30 nov. 2021.

Publicado: 13 dez. 2021.

\section{E-mail para correspondência:}

caroline.passos@gmail.com

Este é um trabalho de acesso aberto e distribuído sob os Termos da Creative Commons Attribution License. A licença permite $o$ uso, a distribuição e a reprodução irrestrita, em qualquer meio, desde que creditado as fontes originais.

Imagem: StockPhotos (Todos os direitos reservados).

(c) (i) Open Access

Resumo: Produtos de marca própria não eram bem aceitos pelos consumidores, mas alguns fatores têm motivado a sua escolha, dentre preço, qualidade e diversificação. Considerando que atualmente, o contrato de private label, tem sido identificada como oportunidade de negócios entre grandes e pequenas empresas, o objetivo deste artigo é apresentar o resultado de um projeto de fabricação de produto inovador através de contrato entre uma indústria de grande porte e uma pequena empresa, elencando principais ganhos e perdas, para auxiliar pequenas empresas na avaliação da viabilidade técnica do contrato de private label. A pesquisa é composta da análise de dados existentes através de pesquisa bibliográfica, fontes em base de dados eletrônicos e observação durante a execução de contrato de private label. 0 resultado obtido não atingiu o mesmo nível de satisfação desejado para todos os envolvidos, mas a experiência pode contribuir para que parcerias similares alcancem melhores resultados.

\section{Palavras-chave: Marca própria. Oportunidade. Pequena e Grande Empresa.}

Abstract: Private label products were not well accepted by consumers, but some factors have motivated their choice, among price, quality and diversification. Considering that currently, the private label contract has been identified as a business opportunity between large and small companies, the purpose of this article is to present the result of an innovative product manufacturing project through a contract between a large industry and a small company, listing the main gains and losses, to assist small companies in evaluating the technical feasibility of the private label contract. The research is composed of the analysis of existing data through bibliographic research, sources in electronic databases and observation during the execution of a private label contract. The result obtained did not reach the same level of satisfaction desired for everyone involved, but the experience can contribute to similar partnerships achieving better results.

Keywords: Private label. Opportunity. Small and Large companies. 
Introdução

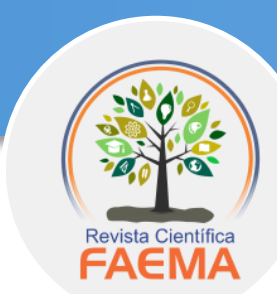

Abordada em pesquisas da área de administração e marketing, que exploram o perfil e tendência de consumo, a marca própria é um tipo de terceirização da produção, em que uma empresa contrata outra para o desenvolvimento de um serviço ou produto com o seu nome/marca.

Em países mais desenvolvidos, a comercialização de marca própria ainda está em expansão, apesar da curva de crescimento não ser ascendente, visto que há uma retração no crescimento da população (menores taxas de crescimento / mercados emergentes - leste europeu e asiático, américa latina) ${ }^{(1)}$. Na Suíça e Alemanha, os produtos alimentícios de marca própria representam 30\% e na Inglaterra cerca de $50 \%$, destaque para o varejista inglês Mars \& Spencer, que vende $100 \%$ dos produtos com marca própria. Enquanto isso, no Brasil, ainda não ultrapassaram 10\% das vendas (2).

Não diferente de outros países, a marca própria iniciou no Brasil pelas cadeias de supermercados, surgindo na década de 1960 com os supermercados Sendas e Paes Mendonça e, dez anos depois, com as redes Wal Mart, Pão de Açúcar e Carrefour que começaram a oferecer produtos com a sua marca, a preços competitivos, como estratégia de branding e para aumentar o mix de produtos nas gôndolas ${ }^{(3)}$.

Alguns fatores têm motivado a escolha de ter produtos de marca própria, dentre eles aumento do poder de negociação e a diminuição de preços para o consumidor. No entanto, o preço praticado é importante, mas não garante a recompra do consumidor; a qualidade é um dos principais atributos para a boa aceitação do produto de marca própria; desconhecer ou ignorar expectativas do seu público alvo é uma falha colossal dos gestores de negócios (4).

Após um estudo sobre o comportamento e hábitos de consumo, Nielsen criou 5 perfis para o consumidor brasileiro - Consciente Pragmático, Equilibrista, Consciente Sonhador, Conectado, Aspiracional - com intuito de auxiliar as estratégias das empresas ${ }^{(5)}$. 


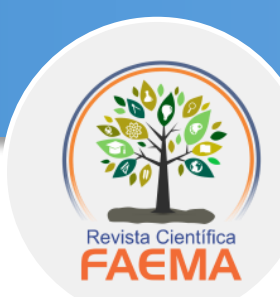

Reconhecer as necessidades, se antecipar as futuras demandas e estar orientadas para o mercado consumidor é a chave para que as empresas sejam competitivas. Quanto maior a renda familiar dos brasileiros, mais eles consideram qualidade e menos eles consideram preço entre os fatores mais importantes na compra de bens de maior valor ${ }^{(6)}$. A marca/fabricante é considerada entre os dois fatores mais importantes por 34\% da população.

Com intuito de acompanhar as tendências e anseios de consumidores cada vez mais exigentes e acelerados, indústrias de alimentos de grande porte têm buscado parcerias com micro e pequenas empresas (MPE) para firmar contrato de private label.

A pequena empresa é uma entidade específica, com problemas administrativos substancialmente distintos quando comparados com a grande empresa, mas uma característica das pequenas empresas é a diferenciação em contraste com a produção em grande escala de produtos padronizados das grandes empresas, que significa altos custos sem oferecer vantagem objetiva. No entanto, pode representar significativa oportunidade para pequenas empresas voltadas a oferecer produtos que atendam às necessidades de consumidores desejosos de independência com relação a produtos massificados ${ }^{(7)}$.

Esse tipo de aliança proporciona que a MPE tenha oportunidade de crescimento, uma vez que permite ampliar produção, aumentar o aproveitamento dos equipamentos e da equipe de produção, reduzindo os custos de processo, ter visibilidade no mercado, bem como, desenvolver novas habilidades e expertises com a parceria.

No cenário atual, essa opção é avaliada por alguns estudiosos como oportunidade para que a empresa se mantenha no mercado, haja visto a crise econômica de ordem mundial ocasionada pela Pandemia COVID-19. É certo que alguns segmentos tiveram aumento de demanda, como produtos para higiene básica, medicamentos, materiais médicos e até algumas categorias de alimentos. 


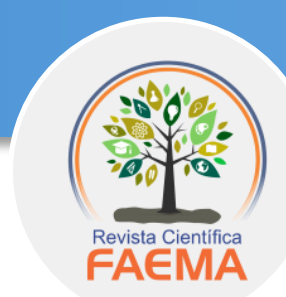

Mas, é possível identificar redução de consumo de alguns produtos alimentícios considerados como supérfluos ou que eram consumidos em ocasiões, agora bastante raras como, cinema, festas, reuniões sociais. Situação imposta pelas medidas restritivas adotadas para conter o avanço da pandemia, uma vez os hábitos alimentares, por exemplo, estão relacionados diretamente aos costumes sociais.

A queda do poder aquisitivo, outro impacto ocasionado pelos reflexos do elevado índice de desemprego ou medidas que permitiram a redução da remuneração salarial (8), impactou diretamente nas escolhas dos consumidores.

Portanto, a redução de custos de produção tem sido cada vez mais condicionante para a sobrevivência das pequenas indústrias. E atrelado a essa condição está o aumento da produtividade. Para medir a capacidade produtiva de uma indústria é necessário conhecimento técnico de cada equipamento individualizado, bem como da linha completa para identificar presença de possíveis gargalos que possam influenciar na redução da eficiência do parque tecnológico. Teorias de produtividade como kaizen, lean manufacturing e outras ferramentas contribuem para análise da situação atual da fábrica. Com base nas informações dos equipamentos e etapas do processo, elabora-se o fluxograma quantitativo, que é de extrema importância para mensurar os indicadores. Todas essas ações, contribuirão para reavaliar a capacidade produtiva, rever e planejar possíveis alianças.

Algo importante também, é a participação ativa dos representantes da empresa em eventos técnicos ou estratégicos para divulgar a marca e apresentar a estrutura que dispõe. Os empresários de um mesmo segmento não devem focar em aspectos de concorrência entre indústrias, mas vislumbrar possíveis parcerias.

Diversificar produção e estar em constante busca por atender as necessidades dos consumidores, cada vez mais exigentes por qualidade e ávidos por inovação requer investimentos de recursos financeiros elevados e tempo - desde aquisição de equipamentos, adequação de espaço físico e desenvolvimento de processos e controles, como testes de desenvolvimento e treinamento de equipe. 


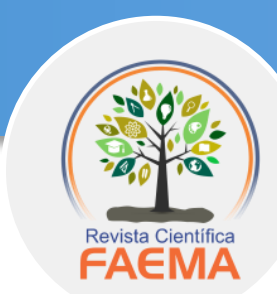

Aliado ao risco do julgamento do mercado consumidor que pode aceitar ou rejeitar o novo produto, o resultado do estudo da análise de risco é primordial para evitar prejuízos. Atrelado à situação atual, onde os investimentos precisam cada vez ser revistos e calculados uma das saídas encontradas tem sido a parceira de terceirização.

Existem quatro possíveis trajetórias de inserção no segmento de consumo: disputa de espaço em mercados ainda pouco oligopolizados e com acentuada concorrência em preços; identificação e exploração de oportunidades em "nichos" de mercado; parte integrante de aglomerações setoriais de empresas, sem liderança explícita; e inserção em redes de relações, mais frequentemente de subcontratação, comandadas por grandes empresas ${ }^{(7)}$. No entanto, projetos em MPE's podem ser diretamente afetados não apenas por mudanças externas, comuns a outras organizações, mas principalmente por diretrizes internas, imaturidade e/ou desconhecimento que promovem impacto negativo no andamento do projeto.

Aliadas aos fatores internos, há também influência causada por mudanças externas que afetam diretamente acordos comerciais e no aspecto sociocultural relacionado com hábitos de consumo que tem sido disseminado cada vez mais rápido, devido a velocidade no compartilhamento de informações. Considerando que os problemas e suas causas não existem isoladamente e que estão intimamente ligados com as pessoas, grupos ou organizações, alguns princípios como comunicação, planejamento e conhecimento de custos de produção, devem ser usados para resolver ou atenuar os problemas e proporcionar êxito num contrato de private label.

A presente pesquisa teve como objetivo analisar a experiência desta autora enquanto Responsável Técnica durante a execução de um projeto de inovação de produção de alimentos em contrato de private label, entre uma indústria multinacional e MPE familiar, elencando principais ganhos e perdas, para auxiliar micro e pequenas empresas (MPE) na avaliação da viabilidade técnica de contrato de private label. 


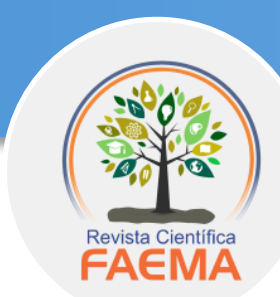

\section{Metodologia}

O presente estudo teve natureza descritiva, composto especialmente de dados existentes através de pesquisa bibliográfica, busca de fontes em base de dados eletrônicos e observação do cenário estudado. Quanto à abordagem, a pesquisa é considerada qualitativa e possui algumas características essenciais, dentre as quais destaca:

- O ambiente natural é a fonte direta de dados;

- O pesquisador é o instrumento fundamental de coleta de dados;

- Procedimentos descritivos da realidade estudada são utilizados;

- Importância do processo e não simplesmente dos resultados e o produto,

- Enfoque indutivo na análise dos dados.

Para esta pesquisa a autora esteve diretamente envolvida nas principais as etapas do projeto, a saber: auditoria para liberação de execução do contrato, monitoramento de todas as etapas de produção e verificação dos resultados, elaboração de relatórios técnicos, liberação do produto final, bem como atendimento ao cliente em questões técnicas e operacionais. A adoção de um critério razoável de julgamento contribui para resultados favoráveis e a abordagem da amostragem é útil quando se faz necessário incluir um pequeno número de unidades na amostra e pode ser, nestes casos, mais fidedigna e representativa que uma amostra probabilística ${ }^{(9,10)}$.

O projeto estudado teve início quando a pequena empresa (PE), participante ativa em feiras de negócios com foco em inovação, sustentabilidade e consumo consciente, estava expondo seus produtos em um evento e atraiu o olhar de representantes do time de desenvolvimento de novos produtos e marketing de uma grande empresa (GE). 


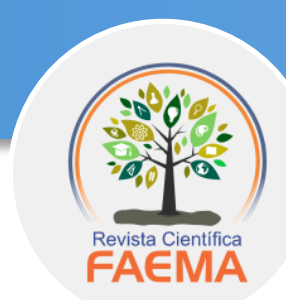

Esta, interessada em diversificar segmento de mercado, com foco nas novas tendências de consumo por produtos orgânicos, saudáveis e diferenciados para atender um nicho de consumidores, encontrou na pequena empresa uma possibilidade para testar o mercado com o lançamento de um produto inovador, sem investimentos elevados.

Após reunião informal no próprio evento, o início da parceria foi marcado por reuniões com as equipes comerciais e de pesquisa e desenvolvimento da GE com um representante da PE. Confirmado o interesse de ambos, seguiu-se a elaboração de um projeto de desenvolvimento do novo produto em parceria e assinatura de termo confidencialidade, por se tratar de um produto inovador no mercado nacional e internacional.

Neste projeto estavam inclusas etapas de visita técnica às instalações da pequena empresa, auditoria de processos pela equipe de produção da GE e testes das formulações dos novos produtos para degustação e análises sensoriais para validação da ficha técnica.

Após as primeiras conversas informais sobre a parceria, a equipe de pesquisa e desenvolvimento da GE, elaborou relatório diagnóstico com base nas informações captadas na visita técnica, onde acompanhou processo de fabricação, conversou com a equipe da PE e analisou documentos técnicos - procedimentos e registros existentes, alvarás, licenças e laudos laboratoriais.

Como resultado da auditoria de processos e considerando que o cliente exigia certificações de qualidade, validadas por órgãos independentes de acreditação, foram identificadas algumas necessidades de melhoria para avançar com a parceria, tais como:

- Adequação na estrutura física da fábrica;

- Manutenção de alguns equipamentos da linha de produção;

- Aquisição de materiais e utensílios para substituição dos existentes; 


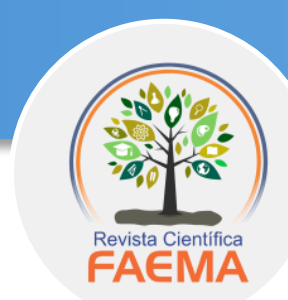

- Renovação/obtenção de licenças específicas;

- Aquisição de novos insumos e materiais de higienização específicos;

- Elaboração de documentos relativos a segurança do trabalho;

- Certificações de qualidade mais rigorosas que as legislações vigentes;

- Implantação de controles de processos e novos indicadores de produção;

- Treinamento da equipe;

- Calibração de equipamentos e instrumentos;

- Aquisição de novos instrumentos para controle de processos;

- Apresentação de plano de manutenção preventiva atualizado.

Diante do resultado da auditoria inicial, a equipe técnica da PE elaborou um plano de ação (imagem 1) para organizar as ações requeridas e responsáveis para acompanhar os prazos de execução e investimento realizado.

Figura 1: Exemplo de Plano de ação

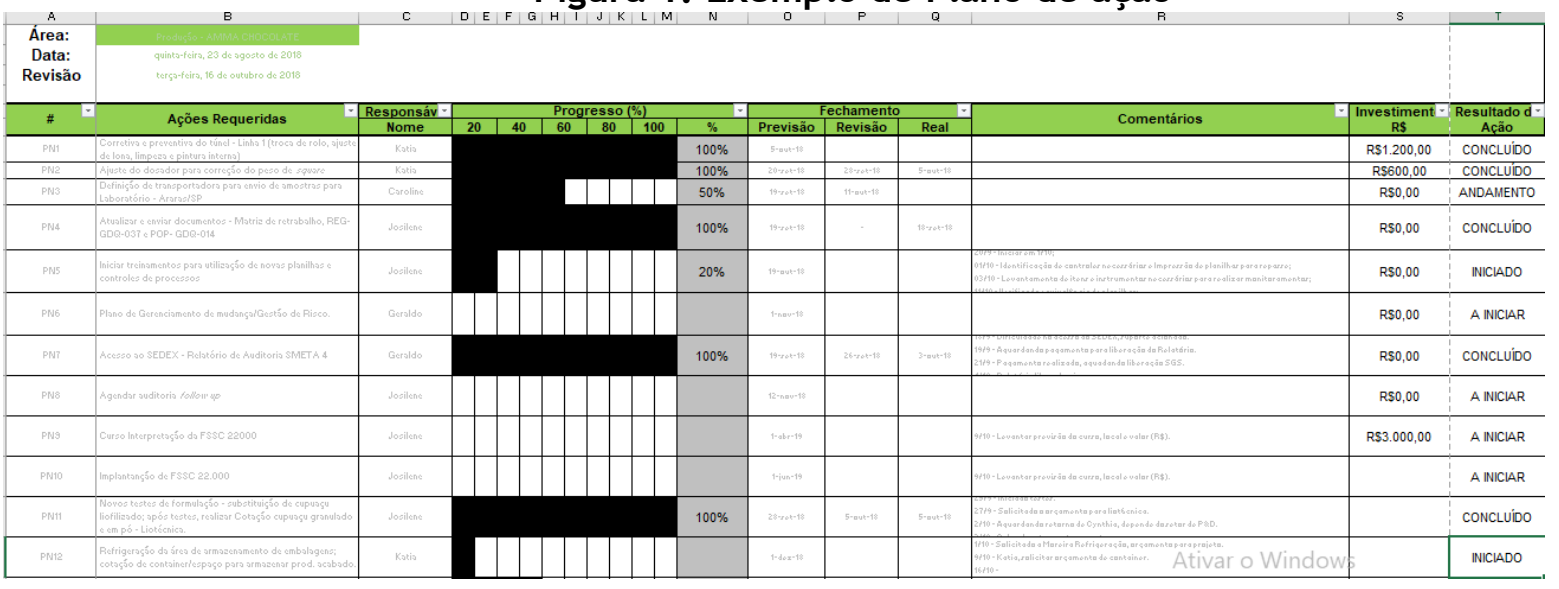




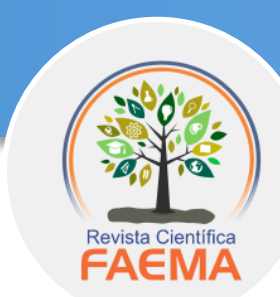

Algumas informações como capacidade produtiva instalada da fábrica, disponibilidade de matéria-prima, principais fornecedores de matérias-primas e prazos de execução (lead time) foram enviadas à equipe da GE, assim como amostras de testes de formulação para análise e validação. Foram realizados alguns ajustes de percentuais de ingredientes e estabelecida a formulação padrão e composição do produto - formato, peso unitário, embalagem primária, secundária e terciária. Com base nessas informações, foram definidos os custos de produção, volume a ser fabricado, prazo e condições comerciais para elaboração de minuta de contrato.

Pari passo, os responsáveis da PE reuniram a equipe da produção, manutenção e administrativa, para informar o interesse na parceria e a necessidade de engajamento de todos para formalização de contrato. Abordaram sobre a importância de executar o plano de ação, respeitando os prazos, uma vez que seria realizada nova auditoria e o resultado desta, seria condição sine qua non para a assinatura do contrato.

As ações que requeriam pouco ou nenhum recurso financeiro foram tratadas de imediato e as demais demandaram visita de prestadores de serviços, apresentação de orçamentos, avaliação das propostas, negociação para redução de valor e forma de pagamento. Semanalmente a equipe envolvida no projeto se reunia para atualização do andamento das etapas e revisão de estratégias para alcançar os objetivos.

Após análise de requisitos do cliente e as mudanças requeridas, foi realizado alinhamento técnico com a equipe de produção que entendeu ser oportuno realizar algumas mudanças no processo atual, aproveitando as melhorias já apresentadas pela parceria. Os colaboradores da produção e qualidade foram treinados para utilização de novos formulários, a fim de se familiarizar com o registro de novos indicadores e rotinas que deveriam ser adotadas quando confirmado o projeto. 


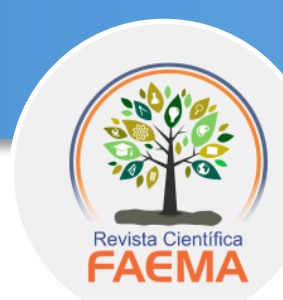

Findado prazo fornecido pela GE, foi realizada visita de auditoria, evidenciado avanços nas melhorias e existência de algumas pendências. Após avaliação de risco, o que ainda tinha sido identificado como não conformidade, mas que não implicaria na segurança do produto, teve prazo ampliado para conclusão e após comprometimento do representante PE, o contrato foi assinado para iniciar produção de marca própria para GE.

Confirmada a capacidade de atendimento da demanda, deu-se início as etapas de definição de obrigações, citando por exemplo o cumprimento do prazo de entrega dos produtos, garantia de fabricação de produto seguro e conforme padrão técnico especificado, bem como das penalidades em caso de qualquer irregularidade identificada ao longo da execução do projeto.

A minuta de contrato de prestação de serviço foi elaborada tendo como base as informações técnicas levantadas nas visitas pela equipe da GE, bem como dados informados pela PE. Nesta etapa foi envolvida a equipe do comercial e marketing das empresas com foco em definição de custos, planejamento de atendimento, forma de pagamento e sanções em caso de descumprimento de alguma cláusula contratual.

Após formalização contratual, foi enviado o primeiro pedido com prazo de entrega pré-definido e acordado entre as partes. As matérias-primas e embalagens foram providenciadas e o start up - início da produção - foi monitorado por integrantes das equipes de produção, qualidade e marketing da GE.

Neste momento, o intercâmbio entre as equipes da PE e GE foi fundamental para o sucesso do projeto. Mesmo com algumas limitações estruturais da PE, foi percebido a dedicação e empenho da equipe perante os representantes da GE.

No acompanhamento do processo, foram percebidos necessidade de ajuste de algumas etapas, formulários e indicadores, por se tratar de uma produção semiautomática, com mais etapas manuais do que numa fábrica automatizada. 


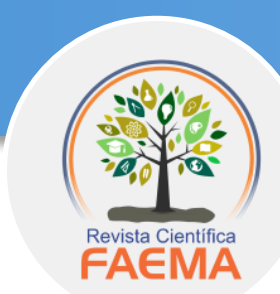

Estar envolvida no contexto estudado, permitiu a pesquisadora uma visão ampla do processo e possibilidade de questionar com mais detalhes as características do objeto de estudo, permitindo capturar elementos objetivos e subjetivos.

Durante a execução do projeto, foi utilizada a técnica da observação como coleta de dados em todas as etapas: leitura do contrato, estudo das legislações, normas e exigências adicionais requeridas pelo Contratante, acompanhamento da execução do plano de ação para correção de não-conformidades apontadas na auditoria da GE, treinamento da equipe dos setores da produção, manutenção e qualidade para utilização de formulários de controle de qualidade, avalição do processo e validação das informações apontadas nos registros e laudos das análises laboratoriais. A observação possibilitou meios diretos e satisfatórios para estudar uma ampla variedade de fenômenos; propiciou a coleta de dados sobre um conjunto de atitudes comportamentais; permitiu obter dados não contemplados em questionários e entrevistas ${ }^{(11,12)}$.

A presente pesquisa demandou conhecimento da legislação vigente para produção de alimentos, segurança do trabalho e questões ambientais, normas de controle de qualidade para que a ferramenta de observação fosse utilizada adequadamente, uma vez que a observadora estava envolvida no objeto de estudo, sendo caracterizada como observação participativa natural ou interna.

A técnica da observação permitiu retratar com realismo o cenário pesquisado e, por ser de natureza participativa, ainda teve como vantagem, a pesquisadora estar familiarizada com o ambiente de produção e com os integrantes das etapas que envolveram o processo de produção, tais como: equipe da produção, logística, financeira e administrativa da Contratada, fornecedores de matéria-prima, prestadores de serviços de análises laboratoriais, equipe de produção, qualidade, marketing e logística da GE. 


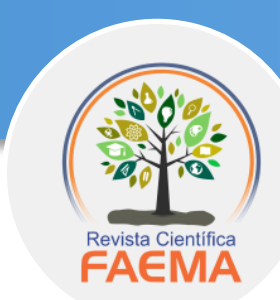

No entanto, observar o contexto natural sem intervenções e evitando favorecer a subjetividade é a estratégica inicial para descrever as observações de maneira imparcial evitando interpretações tendenciosas ${ }^{(12)}$.

Para tanto, a postura profissional ética adotada pela autora, permitiu identificar falhas no processo e corrigi-las a tempo para não impactar no resultado da produção ou, quando necessário interagir com a equipe técnica da GE.

\section{Resultados e Discussão}

O início do contrato de private label, utilizado para o presente estudo, foi marcado por interesses comerciais, tecnológicos e econômicos e gerou expectativas diferentes para PE (Contratado) e GE (Contratante), que culminou em motivações distintas. De um lado uma pequena empresa que vislumbrava a oportunidade de ganhar notoriedade no mercado e reduzir custos de produção, uma vez que ampliaria a utilização dos equipamentos, atingindo capacidade máxima de produção instalada; por outro, uma grande empresa com interesse em testar o mercado consumidor brasileiro para um produto inovador, sem investimento numa nova estrutura fabril.

Para garantir êxito na aliança, a estrutura contratual foi submetida às avaliações e limitações de um conjunto de riscos contratuais. Alinhamento e estreitamento de parceria com os principais fornecedores também foram fundamentais para tentar reduzir ao máximo os problemas relacionados às informações e às incertezas da aliança ${ }^{(13)}$. A adoção de auditorias internas regulares como estratégia para evitar identificar problemas em etapas avançadas do processo que poderia ocasionar prejuízos ao resultado foi um diferencial na execução do contrato. 


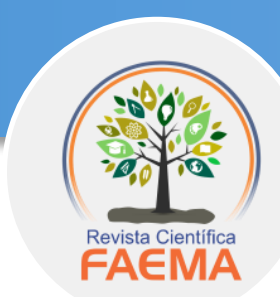

A importância da auditoria interna está principalmente em trabalhar para que haja transparência dos processos e possibilite acompanhar a melhoria dos mesmos, aumentando o valor organizacional do processo; para que isso aconteça, o envolvimento dos funcionários é essencial (14).

Outra ferramenta a ser destacada foi a utilização do plano de ação para planejar a execução das ações. Após reconhecer as não conformidades apontadas nas auditorias, estas foram listadas e estabelecidos cronograma e prazos, informando responsáveis por cada tarefa, recursos financeiros e humanos necessários para êxito do projeto e com intuito de acompanhar a execução de pendências e prazos.

Um plano de ação é estratégico para alcançar o objetivo requerido ${ }^{(15)}$ e é facilmente compreensível por todos os envolvidos. Requer empenho e disciplina para o cumprimento dos prazos, utilização dos recursos e, quando atualizado regularmente, representa um retrato da situação atual, facilitando o monitoramento dos status pelos gestores do projeto.

Com a competitividade cada vez mais presente na economia, os altos custos de produção, surgimento constantes de novos perfis do consumidor, que se apresentam cada dia mais exigentes e menos fieis a marcas, pois conhecem todas as possibilidades de compra existentes, entre outros aspectos, as empresas precisam de melhoria constante em seus processos e saber gerir estrategicamente seus custos e suprimentos, alcançando o aumento da qualidade, e consequentemente, a competividade no mercado ${ }^{(16)}$. Assim, torna indispensável o planejamento e um sistema de gestão de qualidade bem definido e estruturado para evitar prejuízos financeiros e até mesmo da imagem/marca.

$\mathrm{Na}$ etapa de formalização do contrato foi observado maior foco nas vantagens financeiras e comerciais com o resultado da parceria, sendo uma delas a possibilidade de ganhar visibilidade no mercado e abrir caminho para novas parcerias. 


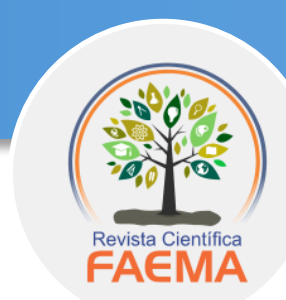

A equipe técnica, responsável efetivamente pela execução do contrato, formada por profissionais da produção e qualidade, ficou limitada a ser fonte de consulta de informações sobre o processo e não participou da avaliação final do contrato. Percebeu-se pouco importância na análise crítica (17) da equipe técnica, quanto à pertinência de algumas exigências, não havendo espaço para adequação e sugestão de margem de segurança para indicadores de qualidade.

No exemplo estudado, o contrato foi firmado com ênfase nas perspectivas comerciais e financeiras, sem considerar questões operacionais e limitações técnicas, sendo esse um dos aspectos mais impactantes na execução do contrato. $\mathrm{Na}$ avaliação comercial, devido desconhecimento técnico e falta de experiência em produção, as obrigatoriedades/exigências do Contratante foram aceitas, mas quando o plano documental passou a ser executado, percebeu-se o elevado custo de investimento necessário para execução do contrato, para evitar pena de sanções por descumprimento do acordado. A não realização de uma análise de riscos, levantamento de limitações e ocorrências não previstas por parte da Contratada, gerou um aumento na pressão sobre a equipe operacional que teve que garantir o cumprimento do planejamento a qualquer custo ${ }^{(17,18)}$.

Finalizada a primeira produção, validada a documentação pela equipe técnica da GE e autorizada a expedição para comercialização dos novos produtos, até então mantidos em sigilo por todos os envolvidos, foi realizada uma reunião de avaliação dos pontos críticos e oportunidades de melhoria para evitar problemas no segundo pedido. A ocorrência mais crítica foi o prazo para execução - divergência entre lead time informado e o realizado.

Por se tratarem de novos produtos com características parecidas, mas não iguais ao já produzido, o comportamento em algumas etapas da produção foi diferente, ampliado o tempo de processo e impactando no aumento de custos com horas extras da equipe para cumprimento do prazo ${ }^{(19)}$. 


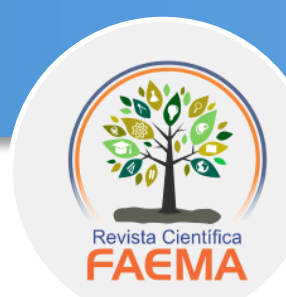

Outro impacto importante foi a parada de produção dos produtos próprios, uma vez que para cumprir prazo de finalização conforme contrato, houve dedicação total da equipe e equipamentos às produções dos novos produtos, ocasionando ruptura no estoque de alguns itens da marca.

Assim, o que no início da parceria era uma oportunidade e só eram percebidas vantagens e aspectos positivos, após execução do contrato, foram destacadas ameaças à 'saúde' financeira da PE, haja visto a necessidade de investimentos necessários para execução do contrato e atendimento às obrigatoriedades impostas pelo Contratante.

A seguir, dois aspectos observados na execução do projeto que, por não terem sido analisados criticamente, impactaram de forma negativa nos resultados do contrato de private label:

1. Capacidade produtiva: precisam ser considerados dados reais de produção e levantados possíveis problemas e fragilidades de processos, requisito para o sucesso de uma nova produção. Do contrário, algumas consequências que podem ser citadas são falhas no planejamento da produção e descumprimento de prazo de entrega, impacto na produção própria, reduzindo estoque e gerando ruptura.

2. Definição dos custos de produção: devem ser considerados custos reais da produção e classificá-los em investimento ou despesa. Negligenciar esta informação, ocasiona resultado financeiro adverso ao esperado, pois para execução do Contrato, as despesas não consideradas no custo do produto, são assumidas pela pequena empresa. No estudo em questão, apenas 30\% dos gastos foram caracterizados como custos de investimento:

2.1. Despesas (70\%): recursos financeiros destinados para aquisição e adequação de itens exclusivos para execução do contrato e que não foram considerados na negociação; brechas no Contrato que permitiu a Contratante ampliar exigências ao longo da execução do mesmo. 


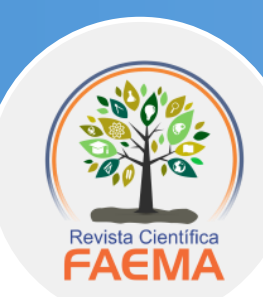

2.2. Investimento (30\%): melhorias cujo benefícios permanecerão após a conclusão do contrato, mesmo que este não seja renovado.

Vale ressaltar que a situação econômica atual causada pela pandemia Covid19, que resultou em queda do poder aquisitivo, tende a aumentar o consumo de produtos de marca própria, uma vez que o custo-benefício pode ser bem menor que as marcas tradicionais. A expectativa é que se repita o mesmo cenário observado em meados de 2008 na Europa, sendo já apontado pelas pesquisas que 50\% do consumo será de produtos de marcas próprias até $2023^{(20)}$, antecipando em 2 (dois) anos a previsão anterior, oportunidade para fabricantes investirem em parcerias para obtenção de produtos inovadores, com qualidade e bom preço com custo de investimento e tempo menores.

\section{Conclusões}

A inexperiência aliada a ausência de análise de risco com base em dados reais de produção, que deveriam ser considerados na elaboração da planilha de custos e minuta, foram aspectos preponderantes no resultado obtido com contrato de private label analisado.

Numa parceria em que seria possível ganho dos dois lados, a realidade foi diferente. Por um lado, a pequena empresa que tinha a possibilidade de reduzir custos de produção, evoluir em aspectos produtivos através da transferência de tecnologia, fortalecer marca, abrir portas para outras parcerias e melhorar a situação financeira da empresa, teve como resultado a redução de estoque do próprio produto, devido necessidade de direcionar recursos para atendimento imediato às demandas do contrato, bem como o aumento de dívidas, devido empréstimos realizados para pagar os investimentos e despesas obrigatórios, aliado ao longo prazo para recebimento do pagamento da produção. 


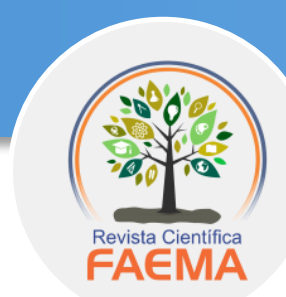

Do outro lado a grande empresa, com a possibilidade de lançar um produto inovador em tempo reduzido sem necessidade de investimentos em aquisição de equipamentos e espaço físico para uma nova linha de produção, com expertise nesse tipo de parceria, considerando que não era o seu primeiro contrato, que do ponto de vista comercial era a mandatória na relação, e que pode testar o mercado consumidor.

Considerando referencial teórico e a experiência no objeto em estudo, é possível afirmar que um dos principais aspectos a serem avaliados em contratos de private label entre empresas de pequeno e grande porte são de ordem técnica operacional - dados reais de produção, capacidade produtiva, equipe necessária, recursos disponíveis para adequações que se obriguem, negociação dos custos de investimento atrelado às exigências adicionais.

A adoção de um programa de auditoria, por ser uma ferramenta estratégica e de grande relevância para obter informações com confiabilidade e credibilidade, a fim de prevenir falha nas avaliações e decisões erradas, também são fundamentais para garantia de sucesso na execução de um contrato de private label.

O resultado obtido não atingiu o mesmo nível de satisfação almejado para todos os envolvidos, mas a experiência obtida ao longo da execução do contrato pode contribuir para que parcerias similares alcancem melhores resultados.

\section{Referências}

1 Neves MF. Um modelo para planejamento de canais de distribuição no setor de alimentos. São Paulo: Universidade de São Paulo; 1999.

2 Associação Brasileira da Indústria de Alimentos - ABIA. Números do setor de alimentos; 2020. [citado 09 de dez. 2020]. Disponível em:

https://www.abia.org.br/downloads/numeros-empregos-ABIA.pdf

3 Yokoyama MH, Silva AL, Piato ÉL. O desenvolvimento de marcas próprias: estudo comparativo entre o varejo e fornecedores da indústria alimentícia. G \& P. 2012; 19(3): 543-556. http://dx.doi.org/10.1590/S0104-530X2012000300008. 


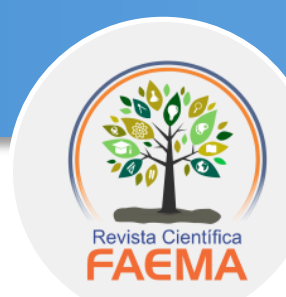

4 Borges LAS. Antecedentes da intenção de compra de marcas próprias: um estudo comparativo entre categorias de alto e baixo risco percebido. São Paulo: FEARP/USP; 2014.

5 Meir R. Os cinco perfis do consumidor no Brasil segundo a Nielsen. Rev Dig Cons Mod. 2019 [citado 05 de fev. 2020]. Disponível em:

https: / /www.consumidormoderno.com.br/2019/06/21/cinco-perfis-consumidor/

6 Confederação Nacional da Indústria - CNI. Retratos da Sociedade Brasileira Perfil do Consumidor: Práticas de Consumo; 2020; 9(50):1-16. Disponível em: https://static.poder360.com.br/2020/01/Pesquisa-CNI-Consumidor.pdf

7 Souza M, Mazzali, L. Conceito e espaço da pequena empresa na estrutura industrial: heterogeneidade e formas de inserção. Rev Gest. Prod. 2008 São Carlos, 15(3): 591-603. Disponível em https://www.scielo.br/pdf/gp/v15n3/12.pdf

8 Diário Oficial da União (BR). Medida Provisória $n^{\circ}$ 1.045, de 27 de abril de 2021, Brasília, 78 (9). [citado 05 de jun. 2021]. Disponível em:

https: / /www.in.gov.br/web/dou/-/medida-provisoria-n-1.045-de-27-de-abril-de2021-316257308

9 Aaker D, Kumar V, Day G. Marketing research. New York: John Wiley \& Sons; 1995.

10 Churchill G. Marketing research: methodological foundations. New York: The Dryden Press; 1998.

11 Marconi MA., Lakatos EM. Fundamentos de metodologia científica. São Paulo: Atlas; 2003.

12 Gil AC. Como elaborar projetos de pesquisa. São Paulo: Atlas; 2002.

13 Sulzbach MT. Marca Própria: Um Capital de Reputação para Distribuidores Varejistas de Alimentos no Brasil. UPF, 2005 Disponível em https: / / silo.tips/queue/marca-propria-um-capital-de-reputaao-para-distribuidoresvarejistas-de-alimentos? $q$ queue_id=-1\&v=1620558197\&u=MTc5LjEwNS4XMzEuMTY2

14 Martinez C. A importância da auditoria de micro e pequenas empresas. Brasil Escola. 2021 [citado 01 de jun. 2021]. Disponível em:

https://monografias.brasilescola.uol.com.br/administracao-financas/aimportancia-auditoriamicro-pequenas-empresas.htm.

15 Petenate M. A importância de um plano de ação para uma empresa. Escola EDTI. 2019 [citado 05 de jun. 2021]. Disponível em: https://www.escolaedti.com.br/aimportancia-de-um-plano-de-acao-para-uma-empresa 


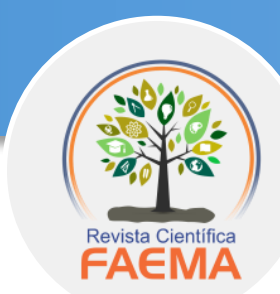

16 Artilha-Mesquita C, Stafussa A, Paraíso C, Rodrigues, L, Silva L, Santos S, et al. Evaluation of Quality Management and its tools: applicability in the animal food industry. Research, Society and Development. 2021; 10 (1): 1-9.

http://dx.doi.org/10.33448/rsd-v10i1.11248

17 Robitaille D. Como tornar a análise crítica adequada e eficaz para a direção. QSP. 2003; 21. Disponível em:

https://www.qsp.org.br/biblioteca/como_tornar.com

18 Santos ER, Silva CR. A influência da auditoria interna no processo decisório organizacional. Rev Est Interdiscip Val Araguaia. 2019; 2(02): 2-19. Disponível em: http://reiva.unifaj.edu.br/reiva/article/view/87

19 Vasconcelos YL, Pereira AC. A importância da auditoria interna no processo decisório das empresas. Rev Bras Contab. 2011; 149: 64-77. Disponível em: http://rbc.cfc.org.br/index.php/rbc/article/view/382

20 Vasconcelos E. Marcas próprias tiveram um grande avanço no novo varejo. Jornal Contábil. 2020. Disponível em: https://www.jornalcontabil.com.br/marcasproprias-tiveram-um-grande-avanco-no-novo-varejo/ 